Bangladesh J. Bot. 42(1): 113-121, 2013 (June)

\title{
BIOMASS ALLOCATION TO VEGETATIVE AND REPRODUCTIVE ORGANS OF CHENOPODIUM ACUMINATUM WILLD. UNDER SOIL NUTRIENT AND WATER STRESS
}

\author{
YingXin Huang*, Xueyong Zhao ${ }^{1}$, Daowei Zhou, Tianhui Wang ${ }^{2}$, \\ GUANDI $\mathrm{LI}^{3}$ AND QIN $\mathrm{LI}^{4}$ \\ Northeast Institute of Geography and Agroecology, Chinese Academy of Sciences, \\ Changchun, 130012, China
}

Key words: Chenopodium acuminatum, Biomass allocation, Plasticity

\begin{abstract}
Biomass allocation was size-dependent. Under soil nutrient, the plasticity of the leaf and reproductive allocation was "true" plasticity, the plasticity of stem allocation was "apparent" plasticity, which is dependent on plant size, but there was no plasticity in root allocation. Under soil water stress, the plasticity of root, leaf and reproductive allocation was "true". In response to population density, the plasticity of stem allocation is "true" plasticity, while the value of the stem allocation is consistent because of the trade off between the effects of plant size and population density. The biomass allocation strategy increases reproductive allocation but decrease leaf allocation with the decrease of soil nutrient, when compared at the same plant size. At lower soil water, the plant allocated more biomass to the root and leaf rather than to reproductive organ.
\end{abstract}

\section{Introduction}

In plants, allocation of the biomass to different organs depends on biotic or abiotic environmental variables, such as soil nutrient, water and population density. According to the optimal allocation theory (Bloom et al. 1985), plant should allocate resources to the organ that acquires the most resource, and often limits the growth. Optimal allocation theory has been applied in many studies (McConnaughay and Coleman 1999). For example, plant allocated more biomass to leaf under low light intensity (Shipley and Meziane 2002), and more biomass to root under low soil nutrient or water (Gonzáles et al. 2008, Mony et al. 2007). However, the optimal allocation theory has also been questioned (Coleman et al. 1994, Huang et al. 2009b, Weiner 2004). The optimal allocation theory suggested that plant allocation is size-independent (Bloom et al. 1985). But Pino et al. (2002) and Ogawa (2003) found that almost all plant allocation patterns are size-dependent. This indicated that the biomass allocation to different organs varied not only with the environments, but also with plant size.

Plants can modify the growth and development in response to changes in environmental conditions (Strand and Weisner 2004). This ability is called plasticity. Many researchers showed that allometric relationships are affected by environment (Allen et al. 2008, Bernacchi et al. 2007, Shipley and Meziane 2002, Wang et al. 2006). The environment may only affect the plant size, but does not change the allometric relationships between different biomass. Thus the difference of plasticity between different environmental factors would disappear when compared at the same plant size. This phenomenon is called "apparent" plasticity. However, the growth ratio of plant may vary with the plant size and plant may change the pattern of biomass allocation themselves in

*Author for correspondence: <huangyx@neigae.ac.cn>. ${ }^{1}$ Cold and Arid Regions Environmental and Engineering Research Institute, Chinese Academy of Sciences, Lanzhou, 730000, China. ${ }^{2}$ School of Life Sciences, Shanghai University, Shanghai, 200444, China. ${ }^{3} \mathrm{E} H$ Graham Centre for Agricultural Innovation (an alliance between Industry \& Investment NSW and Charles Sturt University), Wagga Wagga, NSW, 2650, Australia. ${ }^{4}$ Forage and Gass Department, Sichuan Agricultural University, Yaan 625014, China. 
response to variable environments (Geng et al. 2007, McConnaughay and Coleman 1999, Weiner 2004) which is so-called "true" plasticity. The "apparent" plasticity exists in many plants (Geng et al. 2007, Wang et al. 2006). It is difficult to distinguish between "apparent" and "true" plasticity without a careful study of allometry (McConnaughay and Coleman 1999, Wang et al. 2006). There are allometric relationships among biomass of different organs in many plants (Bernacchi et al. 2007, Huang et al. 2009a, Komiyama et al. 2007, Naumburg et al. 2001). For instance, Peichl and Arain (2007) found allometric relationships between above- and below-ground biomass in 4 age-sequence of white pine (Pinus strobus L.).

Chenopodium acuminatum (Chenopodiaceae) is a weed species in cropland, which is commonly found in the abandoned habitats (Zhao et al. 2005), often in inter-dune lowland and cropland (Peng et al. 2005), which plays an important role in the restoration succession in the degraded sandy land in Horqin Sandland of China. This species shows high phenotypic plasticity and occupies a range of habits differing degree of degraded sandy land and differing land uses (sandy dune, grassland and cropland). Therefore, this species is expected to reveal the strategy of plant in response to variable environments.

The objectives of this study are to answer the following three questions, whether (1) the biomass allocation of C. acuminatum is size-dependent, (2) the plasticity of biomass allocation is "apparent" or "true", and (3) what is the biomass allocation strategy under different environment stress?

\section{Materials and Methods}

Chenopodium acuminatum seeds were collected from a severely degraded sandy site at Naiman County $\left(42^{\circ} 55^{\prime} \mathrm{N}, 120^{\circ} 42^{\prime}\right.$ E, $\left.345 \mathrm{~m} \mathrm{MSL}\right)$ in the centre of Horqin Sandland in the eastern part of Inner Mongolia.

On 9 May 2007, seeds were sown in plastic plates with the sandy soil obtained from the same location where seeds were collected. The soil contained 49 to $53 \mathrm{mg} / \mathrm{kg}$ total nitrogen. At the two-leaf stage (about 2 weeks), the seedlings were transplanted to plastic pots $(13.8 \mathrm{~cm}$ diameter $\times$ $26.5 \mathrm{~cm}$ deep) containing the same soil. Treatments were applied 2 weeks after transplanting.

There were three treatment factors (soil nutrient, soil moisture and plant density) with a $2 \times 2$ $\times 2$ factorial design with 17 or 34 replicates, respectively for high and low plant density ( 816 total plants, 102 plants per treatment). There were two soil nutrient levels. Each pot was applied 0 (N-) or $20 \mathrm{~g}(\mathrm{~N}+$ ) (equivalent to $500 \mathrm{~kg}$ nitrogen per ha) of slow-release fertilizer (Osmocote, containing N 14\%, P $14 \%$ and $\mathrm{K} 14 \%$ and microelements) at the beginning of experiment. For the soil moisture, each pot was watered every 3 days with total amount of 265 (W-) or $530 \mathrm{ml}$ of water $(\mathrm{W}+)$ during experimental period, which was equivalent to 200 or $400 \mathrm{~mm}$ of rainfall during the growing season. There were two plant densities. At high density level, 6 plants in each pot arranged in an equilateral hexagonal fashion pattern (equivalent to 100 plants $/ \mathrm{m}^{2}$ ) and at low density level, 3 plants in each pot arranged in an equilateral triangular pattern (which was equal to 50 plants $/ \mathrm{m}^{2}$ ).

All pots were placed in a greenhouse, which had been ventilated to reduce differences between inside and outside of the greenhouse. In order to avoid edge effect, the pots of each treatment were placed together. The position of pots of each treatment was changed every two weeks.

The plants were harvested on 13 September. A total of 12 - 20 intact plants from each treatment were selected at random for measurement. Each plant was separated into the root, stem, leaf, and reproductive organs (including the rachis, utricles, seeds, perianth segments and bracts). The roots were washed free of soil. Dry weight was determined after oven-drying to a constant 
mass at $80^{\circ} \mathrm{C}$. The following biomass traits were recorded for each individual plant: total biomass, root biomass, stem biomass, leaf biomass, reproductive biomass, shoot biomass (total biomass root biomass), non-stem biomass (total biomass - stem biomass), non-leaf biomass (total biomass leaf biomass), and vegetative biomass (total biomass - reproductive biomass). Biomass allocation traits were calculated as follows: root : shoot ratio (root biomass/shoot biomass), stem : non-stem ratio (stem biomass/non-stem biomass); leaf : non-leaf ratio (leaf biomass/non-leaf biomass) and reproductive effort (reproductive biomass/vegetative biomass).

Data were analyzed with SPSS statistical software (version 11.5) (SPSS Inc., Chicago, Illinois). A three-way analysis of variance was performed to test the main effects of nutrient $(\mathrm{N})$, water (W) and density (D) on biomass allocation and architectural and their interactions.

Regression analysis was conducted to characterize the allometric relationships between root biomass $(y)$ on shoot biomass $(x)$; stem biomass $(y)$ on non-stem biomass $(x)$; leaf biomass $(y)$ on non-leaf biomass $(x)$; and reproductive biomass $(y)$ on vegetative biomass $(x)$ The allometric relationship can be described by $y=b x^{a}$, where $a$ is the scaling exponent (slope) and $b$ is the allometric coefficient or "scaling factor" ( $y$ intercept). Differences in shifting along the slope and in elevation of regression slopes ( $y$ intercept) were assessed using standardized major axis regression (SMA, also known as reduced major axis, RMA) using the R software package (SMATR; Falster et al. 2006, Warton et al. 2006).

\section{Results and Discussion}

The biomass allocation traits were significantly affected by soil nutrient content and water content, while population density had no effect on any traits (Table 1). Root : shoot ratio ranged from 0.036 to 0.224 , stem : non-stem ratio from 0.222 to 0.960 , leaf : non-leaf ratio from 0.002 0.457 , and reproductive effort from 0.264 to 2.224 . Root : shoot ratio was high at low soil water, and stem : non-stem ratio was significantly higher at high soil nutrient. Leaf : non-leaf ratio was significantly high at high soil nutrient or low soil water and reproductive effort was significant high at low soil nutrient or high soil water (Table 1, Fig. 1). There was significant interactions between soil nutrient and soil water for leaf:non-leaf ratio $(\mathrm{p}<0.001)$ and reproductive effort

Table 1. Analysis of variance for the main effects of nutrient, water and plant density, and their interactions on the biomass allocation traits and morphological traits.

\begin{tabular}{lccccc}
\hline Source & df & $\begin{array}{c}\text { Root : shoot } \\
\text { ratio }\end{array}$ & $\begin{array}{c}\text { Stem : non-stem } \\
\text { ratio }\end{array}$ & $\begin{array}{c}\text { Leaf : non-leaf } \\
\text { ratio }\end{array}$ & $\begin{array}{c}\text { Reproductive } \\
\text { effort }\end{array}$ \\
\hline Nutrient & 1 & $3.49^{\text {ns }}$ & $9.52^{* *}$ & $119.27^{* * *}$ & $50.95^{* * *}$ \\
Water & 1 & $7.09^{* *}$ & $1.06^{\mathrm{ns}}$ & $55.57^{* * *}$ & $8.41^{* *}$ \\
Density & 1 & $3.10^{\mathrm{ns}}$ & $2.05^{\mathrm{ns}}$ & $0.07^{\mathrm{ns}}$ & $3.36^{\mathrm{ns}}$ \\
Nutrient $\times$ water & 1 & $3.65^{\mathrm{ns}}$ & $2.33^{\mathrm{ns}}$ & $7.95^{* *}$ & $4.52^{*}$ \\
Nutrient $\times$ density & 1 & $0.02^{\mathrm{ns}}$ & $3.06^{\mathrm{ns}}$ & $0.12^{\mathrm{ns}}$ & $1.71^{\mathrm{ns}}$ \\
Water $\times$ density & 1 & $3.12^{\mathrm{ns}}$ & $0.00^{\mathrm{ns}}$ & $0.00^{\mathrm{ns}}$ & $0.32^{\text {ns }}$ \\
Nutrient $\times$ water $\times$ density & 1 & $1.92^{\mathrm{ns}}$ & $4.78^{*}$ & $2.67^{\mathrm{ns}}$ & $1.35^{\text {ns }}$ \\
\hline
\end{tabular}

${ }^{n s}$ not significant, ${ }^{*} \mathrm{p}<0.05, * * \mathrm{p}<0.01, * * * \mathrm{p}<0.001$. The residual $\mathrm{df}=139$.

$(\mathrm{p}<0.05)$. There was significant 3-way interactions between soil nutrient, soil water and population density for stem : non-stem ratio $(\mathrm{p}<0.05)$. With the exception of root : shoot ratio, the effect of soil nutrient was the largest source of variation in all three biomass allocation traits (Table 1). 
There were significant allometric relationships between root biomass and shoot biomass. The regression slope shifted along common slope and shifted in elevation between soil water treatments (Fig. 2), whereas the regression slope shifted along common slope between soil nutrient treatments or population density treatments (Fig. 2).
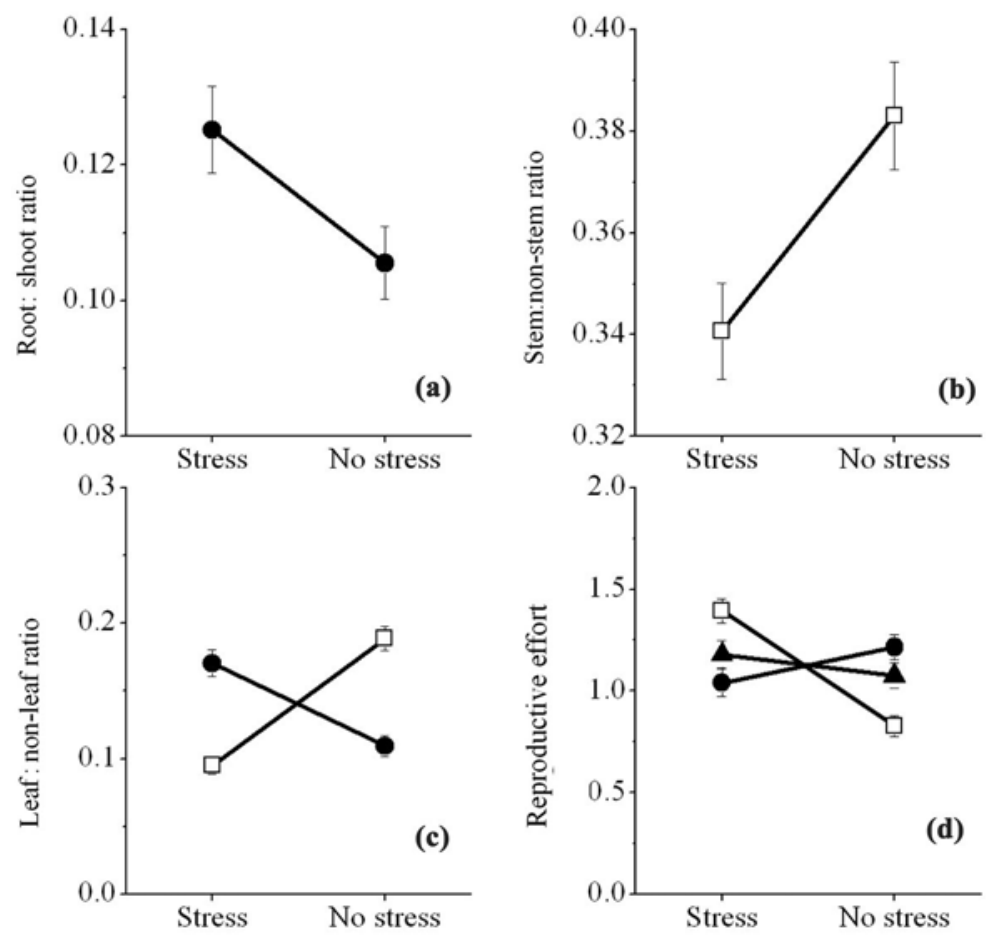

Fig. 1. Biomass allocation traits in response to different stress (mean $\pm \mathrm{SE}$ ). (a) Root : shoot ratio; (b) relative stem biomass, (c) relative leaf biomass and (d) reproductive effort. $\square$ nutrient, $\bullet$ water, $\boldsymbol{\Delta}$ density.

There were significant allometric relationships between stem biomass and non-stem biomass. The regression slope significantly shifted along common slope for soil nutrient or water treatments. However, the regression slope was different between population density treatments (Table 2, Fig. 2).

In all shift along common slope and shift in elevation, the line of increased water was above in root biomass vs. shoot biomass, the line of increasing soil nutrient, and decreasing soil water was above in leaf biomass vs. non-leafbiomass, and the line of increasing soil nutrient, and decreasing soil water was under in reproductive vs. vegetative biomass (Fig. 2).

When the relationships between different organs do not shift or only shift along the common slope, the plasticity is "apparent", which means that the biomass allocation holds the consistent patterns in different environments (Wang et al. 2006, Weiner 2004). These results indicated that root : shoot ratio did not have plasticity in response to soil nutrient. The plants hold the consistent patterns of root allocation in different soil nutrient (Casper et al. 1998). 


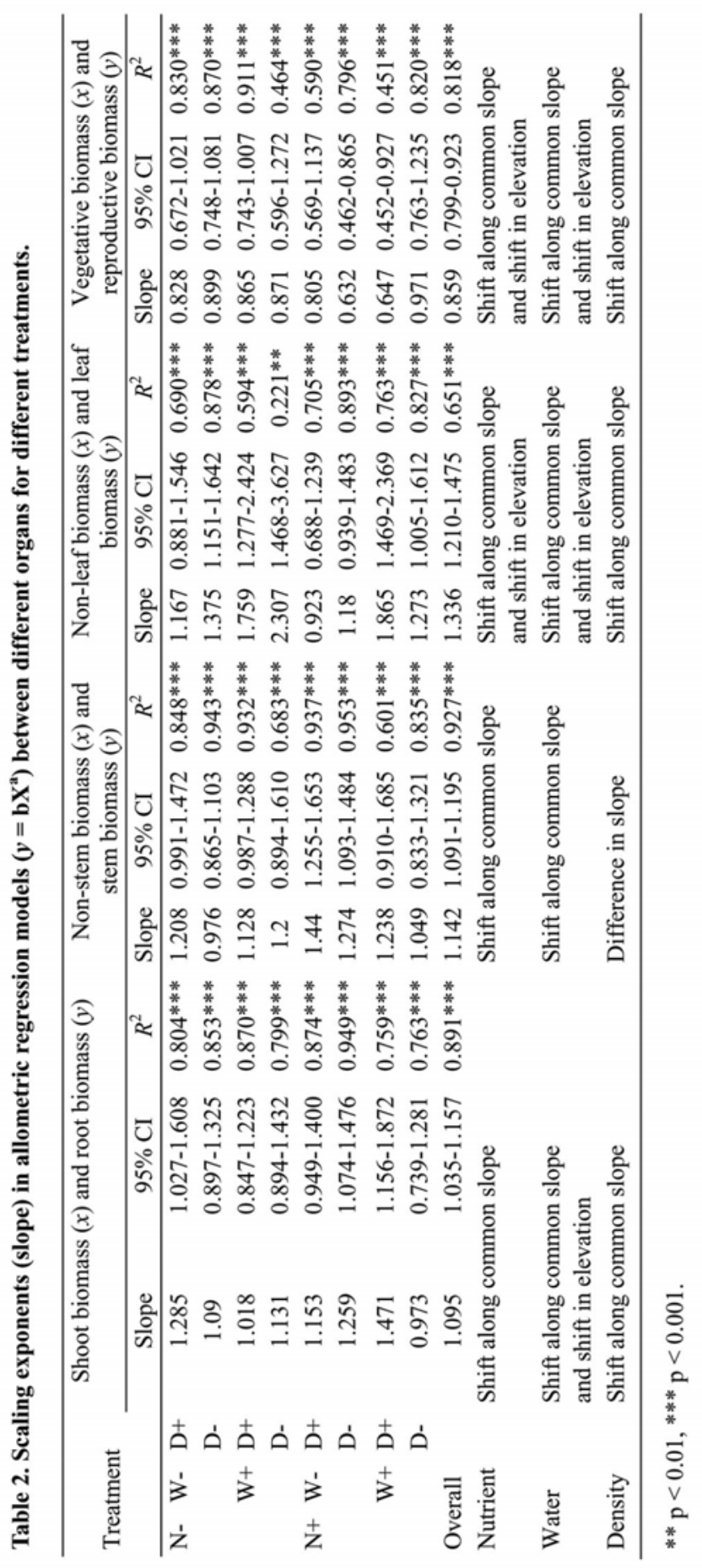


Root biomass increased with increases in soil water. Deficiencies of soil water resulted in high root : shoot ratio. Relatively, more biomass was allocated to the root than to the shoot, and plant allocated more resource to the belowground growth. The allocation also had been observed in other plants (Gonzáles et al. 2008, Mony et al. 2007).

These results indicated that the plasticity of root : shoot ratio in population density treatments was the "apparent" plasticity. So the population density had no effect on the strategy of aboveground and belowground allocation. The population density only affected the plant size. The root : shoot ratio varied with plant size.

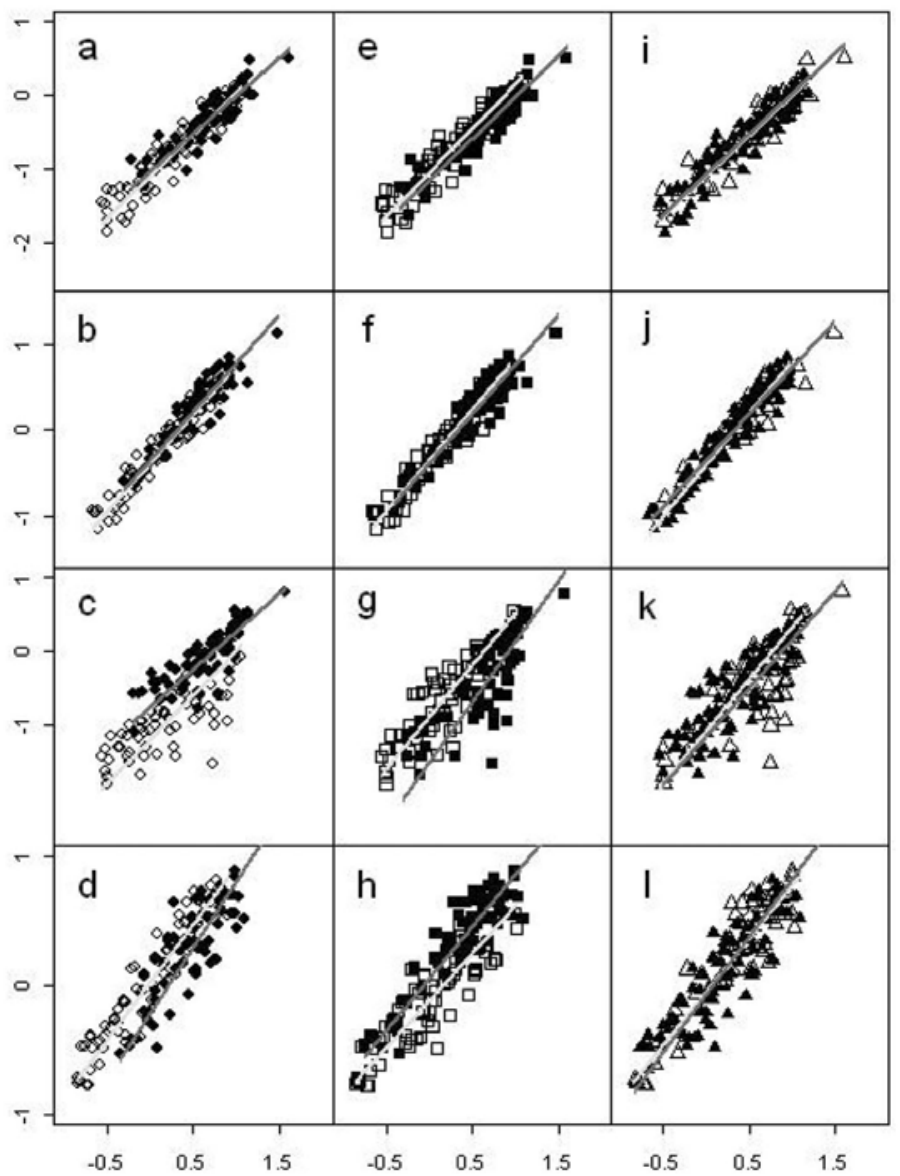

Fig. 2. Log-log plots between organs in response to variation in environment. (a, e, i), Between root (Y) and shoot (X). (b, f, j), Between stem (Y) and non-stem (X). (c, g, k), Between leaf (Y) and non-leaf (X). (d, h, 1), Between reproductive $(Y)$ and vegetative biomass $(X)$. Eight treatments include low nutrient level $(0)$, high nutrient level $(\bullet)$, low water level $(\square)$, high water level $(\bullet)$, low density level $(\triangle)$,high density level $(\boldsymbol{\Lambda})$. The grey and white lines are the reduced major axis regression (RMA) curves for the low level and high level environment, respectively.

The plasticity of stem : non-stem ratio in soil nutrient treatments was the "apparent" plasticity, and stem : non-stem ratio did not have plasticity in response to soil water. The allometric exponent varied with population density, the plasticity of stem : non-stem ratio in population density 
treatments was the "true" plasticity. However, because of the tradeoff between the effects of plant size and soil water content, the stem : non-stem ratio was not varied with soil water.

Present result clearly demonstrated that the leaf allocation was significantly affected by soil nutrient. At fertile soil or deficiencies of soil water, plant allocated more biomass to the leaf (Gindaba et al. 2005, Wang et al. 2008). The allometric relationship between biomass of the leaf and total biomass was affected by soil nutrient and water. The plasticity of leaf : non-leaf ratio to soil nutrient was the "true" plasticity. Both the leaf allocation and the allometric relationship between leaf biomass and non-leaf biomass were not affected by population density. The plant did not have plasticity in response to population density.

Reproductive effort varied with different environmental factors (van Kleunen et al. 2001). For instance, it can either increase (Hickman 1977) or decrease (Snell and Burch 1975) in response to increase in population density. In the present study, density did not have a significant effect on reproductive effort and the allometric relationship between vegetative biomass and reproductive biomass. The plant produced similar reproductive biomass allocation ratios at all densities, which suggested that reproductive effort did not have plasticity in response to population density.

Similar results had been found in such as Atriplex sagittata (Mandak and Pysek 1999), Rumex obtusifolius (Pino et al. 2002) and Plantago major (Reekie 1998). The result supports that subtraction of nutrient can increase reproductive effort, addition of water can increase reproductive effort, and altered density may impose no effect on reproductive effort or the allometry of reproductive biomass.

In conclusion, at lower soil water, the strategy of plant is to allocate more biomass to the root and leaf rather than to reproductive organ. Root, leaf and reproductive allocation did not have plasticity in response to population density. The plasticity of stem allocation is the "true" plasticity, while the value of the stem allocation is consistent because of the tradeoff between the effects of plant size and population density.

\section{Acknowledgements}

The research was supported by a project funding from the National Science Foundation of China (31000216), the Knowledge Innovation Program of the Chinese Academy of Sciences (KZCX2-EW-QN315), and Northeast Institute of Geography and Agroecology, Chinese Academy of Sciences (KZCX3-SW-NA09).

\section{References}

Allen AP, Pockman WT, Restrepo C and Milne BT 2008. Allometry, growth and population regulation of the desert shrub Larrea tridentata. Funct. Ecol. 22: 197-204.

Bernacchi CJ, Thompson JN, Coleman JS and McConnaughay KDM 2007. Allometric analysis reveals relatively little variation in nitrogen versus biomass accrual in four plant species exposed to varying light, nutrients, water and $\mathrm{CO}_{2}$. Plant Cell Environ. 30: 1216-1222.

Bloom AJ, Chapin FS and Mooney HA 1985. Resource limitation in plants - an economic analogy. Annu. Rev. Ecol. Syst. 16: 363-392.

Casper BB, Cahill JF and Hyattl A 1998. Above-ground competition does not alter biomass allocated to roots in Abutilon theophrasti. New Phytol. 140: 231-238.

Coleman JS, McConnaughay KDM and Acherly DD 1994. Interpreting phenotypic variation in plants. Trends in Ecology \& Evolution. 9: 187-191.

Falster DS, Warton DI and Wright IJ 2006. SMATR: Standardised major axis tests and routines, ver 2.0. http://www.bio.mq.edu.au/ecology/SMATR. 
Geng Y, Pan X, Xu C, Zhang W, Li B and Chen J 2007. Plasticity and ontogenetic drift of biomass allocation in response to above- and below-ground resource availabilities in perennial herbs: A case study of Alternanthera philoxeroides. Ecol. Res. 22: 255-260.

Gindaba J, Rozanov A and Negash L 2005. Photosynthetic gas exchange, growth and biomass allcoation of two Eucalyptus and three indigenous tree species of Ethiopia under moisture deficit. For. Ecol. Manage. 205: $127-138$.

Gonzáles WL, Suárez LH, Molina-Montenegro MA and Gianoli E 2008. Water availability limits tolerance of apical damagein the Chilean tarweed Madia sativa. Acta Oecol. 34.

Hickman JC 1977. Energy allocation and niche differentiation in four co-existing annual species of Polygonum in western North America. J. Ecol. 65: 317-326.

Huang YX, Zhao XY, Zhang HX, Huang G, Luo YY and Japhet W 2009a. A comparison of phenotypic plasticity between two species occupying different positions in a successional sequence. Ecol. Res. 24: $1335-1344$.

Huang YX, Zhao XY, Zhang HX, Japhet W, Zuo XA, Luo YY and Huang G 2009b. Allometric effects of agriophyllum squarrosum in response to soil nutrients, water, and population density in the horqin sandy land of China. J. Plant Biol. 52: 210-219.

Komiyama A, Ong JE and Poungparn S 2007. Allometry, biomass, and productivity of mangrove forests: A review. Aquat. Bot. 89: 128-137.

Mandak B and Pysek P 1999. How does density and nutrient stress affect allometry and fruit production in the heterocarpic species Atriplex sagittata (Chenopodiaceae)? Can. J. Bot.77: 1106-1119.

McConnaughay KDM and Coleman JS 1999. Biomass allocation in plants: Ontogeny or optimality? A test along three resource gradients. Ecology 80: 2581-2593.

Mony C, Koschnick TJ, Haller WT and Muller S 2007. Competition between two invasive Hydrocharitaceae (Hydrilla verticillata (L.f.) Royle and Egeria densa Planch) as influenced by sediment fertility and season. Aquat. Bot. 86: 236-242.

Naumburg E, Ellsworth DS and Pearcy RW 2001. Crown carbon gain and elevated $\left[\mathrm{CO}_{2}\right]$ responses of understorey saplings with differing allometry and architecture. Funct. Ecol. 15: 263 - 273.

Ogawa K 2003. Size dependence of leaf area and the mass of component organs during a course of self-thinning in a hinoki (Chamaecyparis obtusa) seedling population. Ecol. Res. 18: 611 -618.

Peichl M and Arain MA 2007. Allometry and partitioning of above- and below ground tree biomass in an age-sequence of white pine forests. For. Ecol. Manage. 253: 68-80.

Peng Y, Jiang GM, Liu MZ, Niu SL, Yu SL, Biswas DK, Zhang Q, Shi X and Yang QS 2005. Potentials for combating desertification in Hunshandak Sandland through nature reserve. Environ. Manage. 35: 453-460.

Pino J, Sans FX and Masalles RM 2002. Size-dependent reproductive pattern and short-term reproductive cost in Rumex obtusifolius L. Acta Oecol. 23.

Reekie EG 1998. An explanation for size-dependent reproductive allocation in Plantago major. Can. J. Bot. 76: 43-50.

Shipley B and Meziane D 2002. The balanced-growth hypothesis and the allometry of leaf and root biomass allocation. Funct. Ecol. 16: 326-331.

Snell TW and Burch DG 1975. The effects of density on resource partitioning in Chamaesyce hirta (Euphorbiaceae). Ecol. Lett. 56: 742-746.

Strand JA and Weisner SEB 2004. Phenotypic plasticity - contrasting species specific traits induced by identical environmental constraints. New Phytol. 163: 449-451.

van Kleunen M, Fischer M and Schmid B 2001. Effects of intraspecific competition on size variation and reproductive allocation in a clonal plant. Oikos 94: 515-524.

Wang J, Yu D and Wang Q 2008. Growth, biomass allocation, and autofragmentation responses to root and shoot competition in Myriophyllum spicatum as a function of sediment nutrient supply. Aquat. Bot. 89: $357-364$. 
Wang T, Zhou D, Wang P and Zhang H 2006. Size-dependent reproductive effort in Amaranthus retroflexus: The influence of planting density and sowing date. Can. J. Bot. 84: 485-492.

Warton DI, Wright IJ, Falster DS and Westoby M 2006. Bivariate line-fitting methods for allometry. Biological Reviews 91: 259-291.

Weiner J 2004. Allocation, plasticity and allometry in plants. Perspectives in Plant Ecology Evolution and Systematics 6: 207-215.

Zhao WZ, Xiao HL, Liu ZM and Li J 2005. Soil degradation and restoration as affected by land use change in the semiarid Bashang area, northern China. Catena 59: 173-186.

(Manuscript received on 18 July, 2012; revised on 6 December, 2012) 